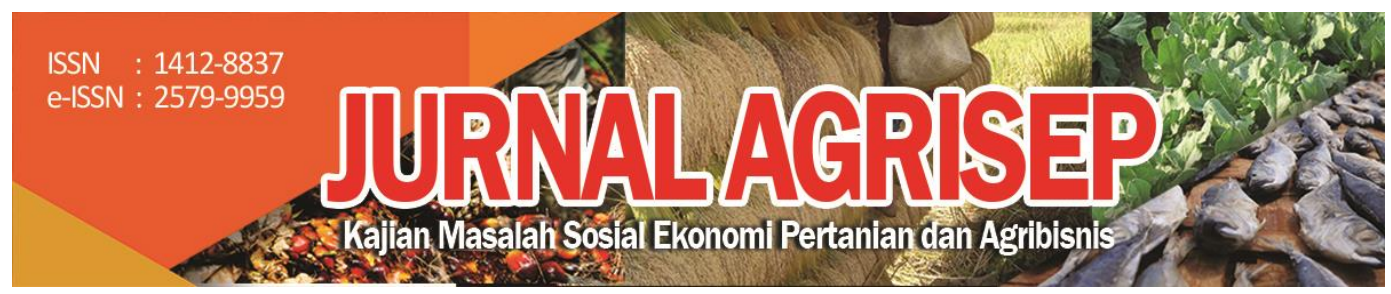

DOI: 10.31186/jagrisep.17.2.321-332

\title{
BLUE OCEAN STRATEGY PADA USAHA PENGOLAHAN KOPI “UD TYYANA COFFEE" DI KABUPATEN TAPANULI SELATAN
}

\author{
Blue Ocean Strategy On Coffee Processing Business "UD Tyyana \\ Coffee" In South Tapanuli Regency
}

\author{
Yulia Windi Tanjung1) ; Anugrah Sri Widiasyih'2) \\ ${ }^{122)}$ Dosen Prodi Agribisnis Fakultas Pertanian Universitas Graha Nusantara \\ Email :winditanjung@gmail.com
}

\begin{abstract}
Coffee (Coffeea sp.) is an agricultural commodity in the plantation subsector which includes the mainstray export commodity, has high economic value and an important source of foreign exchange (net exporters) for Indonesia. UD Tyyana Coffee is one of the busnisesses that runs agribusiness of coffee commodities ranging from plantations to coffee processing. The aims of this study is to analyze the Blue Ocean Strategy at UD. Tyyana Coffee in the South Tapanuli Regency. This study uses a qualitative descriptive method. The result of the research is in running a large strategic series, UD Tyyana Coffe breaks down strategies that are not yet owned by competitors, such as (1) Improving product quality and HR will provide benefits to consumers by providing maximum results. Creating a trend of locations with cafe nuances and facilities such as homestays will increase the emotional appeal of consumers; (2) In the formulation of the Blue Ocean Strategy, the price offered by UD Tyyana Coffee is very attractive and does not change, so it does not affect consumer purchasing power; (3) The costs incurred for this strategy are still affordable. By improving service, it is only intensified when serving ground coffee to provide education about coffee; (4) Adopting the Blue Ocean Strategy requires commitment and cooperation in its processing.
\end{abstract}

Keywords: Blue Ocean Strategy, Coffee, South Tapanuli Regency

\begin{abstract}
ABSTRAK
Kopi (Coffeea sp.) merupakan komoditas pertanian di subsektor perkebunan yang termasuk komoditas ekspor andalan, memiliki nilai ekonomis yang tinggi dan sumber
\end{abstract}


devisa (net exporter) penting bagi Indonesia. UD Tyyana Coffee adalah salah satu usaha yang menjalankan agribisnis komoditas kopi mulai dari perkebunan hingga pengolahan kopi. Tujuan penelitian adalah menganalisis strategi Samudra Biru di UD Tyyana Coffee. Metode Penelitian menggunakan deskriptif kualitatif metode. Hasil dari penelitian yaitu dalam menjalankan seri strategis yang besar, UD TyyanaCoffee memecah strategi yang belum dimiliki oleh kompetitor, seperti (1) Meningkatkan kualitas produk dan SDM akan memberikan manfaat bagi konsumen dengan memberikan hasil yang maksimal. Menciptakan tren lokasi dengan nuansa kafe dan fasilitas seperti homestay akan meningkatkan daya tarik emosional konsumen; (2) Dalam perumusan Blue Ocean Strategy, harga yang ditawarkan UD Tyyana Coffee sangat menarik dan tidak berubah, sehingga tidak mempengaruhi daya beli konsumen; (3) Biaya yang dikeluarkan untuk strategi ini masih terjangkau. Dengan meningkatkan pelayanan, hanya diintensifkan saat menyajikan kopi bubuk untuk memberikan edukasi tentang kopi; (4) Mengadopsi Strategi Samudra Biru membutuhkan komitmen dan kerjasama dalam pengolahannya.

Kata Kunci: Blue Ocean Strategy, Kopi, Kabupaten Tapanuli Selatan

\section{PENDAHULUAN}

Kopi (Coffeea sp.) merupakan komoditas pertanian di subsektor perkebunan yang termasuk komoditas ekspor andalan, memiliki nilai ekonomis tinggi dan sumber devisa (net exporter) penting bagi Indonesia (Hadi, 2011). Kopi termasuk terbesar kedua setelah petroleum dalam dunia perdagangan internasional (Mussatto, 2011). Kabupaten Tapanuli Selatan merupakan daerah yang memiliki potensi untuk perkebunan kopi dimana sesuai dengan ketinggian tempat penanamannya yaitu diantara 0 sampai $1.985 \mathrm{~m}$ dari permukaan laut (mdpl) dengan curah hujan $2.362 \mathrm{~mm}$ pertahun (BPS Kabupaten Tapanuli Selatan, 2017).

Mengkonsumsi kopi sudah menjadi gaya hidup masyarakat dimana bisa membuka peluang bisnis yang besar sehingga industri kopi berkembang signifikan (Mustamu, 2013). Tingginya tingkat persaingan diantara produsen atau pebisnis kopi yang ketat dan kompetitif menjadikan ancaman bisnis. Dalam membentuk trend pasar baru tentunya produsen dapat melihat peluang pasar yang belum tergarap. Hal ini menciptakan kondisi yang mampu menguntungkan bagi usahanya dengan menghadirkan inovasi dan ciri khasnya masing-masing. Kualitas kopi yang dikonsumsi dapat dilihat dari citarasa, warna dan aroma (Sari, 2018). UD Tyyana Coffe merupakan salah satu usaha agribisnis kopi mulai dari hulu yaitu budidaya atau perkebunan hingga agroindustri atau pengolahan kopi yang berlokasi di Desa Aek Sabaon, Kec. Marancar, Kab. Tapanuli Selatan. UD. Tyyana Coffee memiliki ciri khasnya “dari kebun ke cangkir" dimana kopi langsung di panen dari kebun milik sendiri dan diolah langsung di kedai kopi yang lokasinya di dalam perkebunan kopi. 
Banyaknya tantangan mulai dari kegiatan budidaya hingga pemasaran produk, tingginya tingkat persaingan yaitu menjamurnya usaha-usaha baru dengan inovasi yang berbeda serta kualitas cita rasa kopi yang spesialty dari dalam atau luar negeri membuat UD. Tyyana Coffee harus dapat menciptakan strategi agar dapat bertahan di usaha pengolahan kopi.

Blue ocean strategy merupakan salah salah satu strategi untuk mengalahkan pesaing melalui penawaran spesifikasi produk yang inovatif ditandai dengan pasar yang belum tereksplor, menciptakan permintaan dan peluang bertumbuh yang menguntungkan. Pelaku bisnis dipacu untuk masuk ke pasar baru yang potensial seakan terabaikan pesaing (Kim, 2006). Blue ocean strategy adalah suatu strategi bisnis yang dijalankan oleh suatu perusahaan atau usaha dengan menekankan nilai inovasi dimana hanya dimiliki oleh usaha tersebut sehingga memiliki keunggulan kompetitif dibanding dengan pesaing (Kim, 2006). Inovasi nilai adalah cara yang baru untuk merencanakan dan mengimplementasikan startegi yang mengarah kepada meningkalkannya kompetisi dan menciptakan samudera biru (Hermato, 2011). Untuk bertahan dan meningkatkan kemampuan kompetitifnya, strategi dapat disesuikan mengikuti dunia bisnis yang berubah dalam mengembangkan inovasi kompetitif berkelanjutan (Walker, 2009). Keterbaruan penelitian ini yaitu menganalisis blue ocean strategi usaha pengolahan kopi secara kompleks mulai dari kegiatan usahatani, pengolahan serta pemasaran produk kopi. Tujuan penelitian ini yaitu untuk menganalisis Blue Ocean Strategy pada bisnis pengolahan kopi "UD Tyyana coffee" di Kabupaten Tapanuli Selatan.

\section{METODE PENELITIAN}

Penelitian dilakukan di UD Tyyana Coffee, Desa Aek Sabaon, Kec. Marancar, Kab. Tapanuli Selatan, Prov. Sumatera Utara. Pemilihan lokasi penelitian secara sengaja (purposive). Data yang digunakan yaitu data primer dan sekunder. Metode pengumpulan data yaitu observasi, survey dengan kuesioner (angket), FGD serta wawancara mendalam (indepth interview). Metode analisis data yaitu analisis deskriptif kualitatif. Teknik analisa data menggunakan analisis Blue Ocean Strategy, mengidentifikasi sumberdaya yang dimiliki oleh UD. Tyyana Coffee. Tahap awal perumusan Blue Ocean Strategy dengan eksplorasi visual kerangka 6 jalan, yaitu (a) mengidentifikasi industri alternatif, (b) mencermati kelompok strategis dalam industri, (c) mencermati rantai konsumen atau rantai pembeli, (d) mencermati cakupan penawaran produk atau jasa komplementer/pelengkap, (e) mencermati daya tarik fungsional dan emosional, dan (f) mencermati waktu. Tahap Kedua menggunakan strategi kanvas dengan merangkum serta menjelaskan faktor bisnis yang diperoleh pembeli, merangkum situasi kondisi pasar. Tahap Ketiga menggunakan kerangka kerja 4 langkah (four action framework) dengan melihat faktor-faktor yang dikurangi (Reduce), dihapuskan (Eliminate), ditingkatkan 
(Increase), serta diciptakan (Create). Tahap akhir merumuskan serta mengeksekusi Blue Ocean Strategy yang tepat untuk UD Tyyana Coffee.

\section{HASIL DAN PEMBAHASAN}

\section{FORMULASI BLUE OCEAN STRATEGI}

Formulasi Blue Ocean Strategi pada UD. Tyyana Coffee dapat dilihat dari beberapa prinsip berikut:

\section{Prinsip 1: Merekonstruksi Batasan-Batasan Pasar}

Batasan-batasan pasar di dalam Blue Ocean Strategy adalah bukan diperebutkan melainkan diciptakan, sehingga UD. Tyyana Coffee melakukan rekonstruksi terhadap batasan-batasan pasar kembali melalui keragka kerja 6 jalan berikut:

\section{Mengidentifikasi Industri Alternatif}

Industri alternatif yaitu industri yang menghasilkan produk atau jasa yang menawarkan fungsi dan manfaat inti/utilitas yang sama namun memiliki bentuk atau jenis yang berbeda (Pasolang, 2012). UD. Tyyana Coffee memiliki motto "Dari Kebun Ke Cangkir" yaitu dengan memiliki lahan budidaya kopi milik sendiri dan mendirikan kedai kopi langsung di areal lahan, selain itu kopi yang telah dipanen langsung di produksi sendiri berupa olahan biji kopi (kopi bubuk, roast bean, green bean). Sehingga, industri alternatif dari UD. Tyyana Coffee yaitu industri pendidikan yang menawarkan fungsi edukasi kepada pengunjung. Menurut McMillan dalam (Pasolang, 2012) perilaku individu terhadap lingkungan berhubungan positif dengan tingkat pendidikan. Saat berkunjung pemilik akan memberikan berbagai edukasi mengenai kopi mulai dari budidaya hingga pemasaran. Selain itu industri alternatif lainnya seperti industri agrowisata dan wisata kuliner yang memberikan fungsi kesenangan bagi pengunjung, produk yang dihasilkan agrowisata adalah barang dan jasa. Barang diperoleh dari hasil usahatani sedangkan jasa dihasilkan dari produksi layanan dan kinerja karyawan (Putri, 2018). Industri alternatif lainnya yaitu industri minuman yang menawarkan produk berbagai minuman yang cepat saji. Industri-industri tersebut memiliki fungsi yang sama dengan UD. Tyyana Coffee yaitu fungsi edukasi, fungsi kesenangan, fungsi penawaran produk minuman.

\section{Mencermati Kelompok Strategis di Industri}

Dalam industri terdapat kelompok strategis yaitu kelompok organisasi/perusahaan di satu industri yang memiliki persamaan strategi

324 | Yulia Windi Tanjung dan Anugrah Sri Widiasyih; Blue Ocean Strategy... 
(Andriani, 2012). UD. Tyyana Coffee cukup banyak memiliki pesaing dimana memiliki target pasar dan strategi sama yaitu produk olahan kopi premium. Produk biji kopi sangat banyak dan mudah didapatkan di pasar, namun masih jarang yang benar-benar fokus terhadap produk dari hulu ke hilir didalam satu industri yang sama. Dengan harga yang ekonomis, kualitas premium, dan pengetahuan tentang kopi diberikan langsung ke konsumen. UD. Tyyana Coffee menganggap tidak memiliki pesaing dengan industri yang sama seperti UD. Tabo Kopi Sipirok, dan PDM Coffee meskipun memiliki target pasar yang sama, menjual jenis kopi sipirok dan kebanyakan memiliki strategi yang sama. Masing-masing kelompok strategis dalam industri bekerja sama dalam memenuhi permintaan konsumen apabila stok produksi tidak memenuhi permintaan konsumen maka UD. Tyyana Coffee akan menawarkan produk UD. Tabo Kopi Sipirok, dan PDM Coffee ke konsumen dengan catatan harus menggunakan merek dagang masing-masing industri yang ditawarkan. Begitupun sebaliknya dengan industri lainnya. Kerjasama bisnis sangat dibutuhkan untuk meraih keuntungan bersama dengan prinsip saling membutuhkan dan membesarkan (Chandra, 2014). Kelompok strategis tidak terlihat bersaing dikarenakan kelompok strategis memiliki sudut pandang permintaan yang beda (Andriani, 2012).

\section{Mencermati Rantai Konsumen atau Rantai Pembeli}

Rantai konsumen atau rantai pembeli dapat terlibat langsung maupun tidak langsung di dalam industri dalam proses pembelian produk atau jasa. Rantai pembeli yaitu pembeli melakukan pembayaran, pemberi pengaruh dalam pembelian, dan pengguna produk. Rantai pembeli pada UD. Tyyana Cofffe ada 2 saluran yaitu saluran 1. UD. Tyyana Coffee langsung ke Konsumen dan saluran 2: UD. Tyyana Coffee - kafe-kafe di Tapanuli Bagian Selatan (Konsumen 1) - pembeli akhir (Konsumen 2). Fokus pemasaran langsung kepada konsumen dengan cara membuka kedai kopi yang menyajikan minuman kopi dengan sistem pembayaran suka rela konsumen, diharapkan dengan secangkir kopi dapat mempererat persaudaraan antara konsumen dan produsen. Konsumen yang loyal akan dengan sendirinya mempromosikan produk kepada kerabat terdekatnya. Pelanggan yang loyal akan memberikan keuntungan dan kepercayaan yang besar (Mardalis, 2005). Selain itu juga memasarkan produk olahan biji kopi dalam kemasan untuk konsumen akhir lokal maupun mancanegara secara langsung tanpa bantuan agen/pedagang perantara dengan sistem pembayaran tunai maupun dengan transfer. 


\section{Mencermati Cakupan Penawaran Produk atau Jasa Pelengkap}

Penawaran produk atau jasa pelengkap sangat berpengaruh terhadap nilai yang didapat konsumen karena nilai dapat ditingkatkan oleh perusahaan dengan menawarkan kemudahan mengetahui fungsi barang atau jasa pelengkap (Andriani, 2012). Untuk meningkatkan cita rasa kopi UD. Tyyana Coffee bekerjasama dengan industri gula semut atau gula aren sebagai produk pelengkap. UD. Tyyana Coffee juga menyediakan makanan pendamping saat menikmati minuman kopi di kedai. Lokasinya juga dekat dengan industri d bidang pariwisata Aek Sabaon, dan areal playground Sibio-bio Adventure Park sehingga dapat bekerja sama dengan industri tersebut.

\section{Mencermati Daya Tarik Fungsional dan Emosional}

Perusahaan sangat berfokus kepada daya tarik fungsional dan emosional (Andriani, 2012). UD. Tyyana Coffee sangat memiliki daya tarik fungsional dan emosional dengan memproduksi produk kualitas premium dimulai dengan proses budidaya kopi yang semi organik dan menerapkan sistem tanam tumpang sari dengan tanaman jeruk dan sengon yang memberikan cita rasa asam jeruk pada buah kopi. Selanjutnya proses produksi yang hieginies dan murni tanpa campuran bahan kimia berbahaya, serta proses penyajian produk di dalam kedai langsung menyeduh kopi di depan konsumen sehingga konsumen dapat mengetahui langsung proses penyeduhan kopi. Owner sudah memiliki sertifikat kompetensi di bidang kopi. Untuk dapat meningkatkan dayatarik emosional dapat juga dengan menambahkan atribut yang dapat digunakan sebagai hiburan bagi para konsumen (Andriani, 2012). Untuk kopi kemasan, sebelum dipasarkan ke konsumen terlebih dahulu diberikan edukasi. Produk juga sudah lulus sertifikasi BPOM, halal MUI dan uji mutu. Konsumen yang datang ke kedai dilayani dengan sangat baik dengan sistem kekeluargaan sehingga konsumen menjadi loyal.

\section{Mencermati Waktu}

Perusahaan atau industri harus dapat mencermati waktu karena sebuah perusahaan atau industri dituntut dapat menawarkan nilai yang lebih kepada konsumen di masa sekarang dan yang akan datang. UD. Tyyana Coffee sangat melihat tren meminum kopi sebagai way of life di Indonesia menjadikan industri kopi berkembang pesat. Meminum kopi kualitas premium biasanya lebih tren dikalangan ekonomi menengah keatas. Namun UD. Tyyana Coffee berusaha mencoba berinovasi agar kalangan ekonomi menengah kebawah juga dapat menikmatinya yaitu dengan menjadikan kedai kopi yang dapat diakses oleh semua kalangan 
namun tetap berkualitas premium. Dengan mencermati waktu, perusahaan tidak hanya menyesuaikan tindakan atau strategi bisnis mereka dengan mengikuti perkembangan tren yang diamati namun juga ikut dalam membentuk tren baru (Wadud, 2010).

\section{Prinsip 2: Fokus Gambaran Besar, Bukan Angka}

Merumuskan Blue Ocean Strategy pada langkah kedua yaitu tidak hanya berfokus pada angka, namun fokus pada gambaran yang besar. Resiko perencanaan pada investasi baik modal, sumberdaya manusia dan waktu yang berlebih dalam persaingan bisnis dapat dikurangi dengan prinsip ini (Utomo, 2010). Terdapat pendekatan alternatif untuk proses perencanaan strategis berikut:

\section{Canvas Strategy}

Canvas strategy merupakan action framework dan diagnosis dalam membagun blue ocean strategy (Kho, 2014). Dalam pembuatan strategi canvas sangat memperhatikan berbagai faktor internal industri maupun pesaing. Kanvas strategi yang dimiliki industri digunakan untuk membandingkan bisnis yang dimiliki oleh industri dengan pesaing. Pesaing dari UD. Tyyana Coffee yaitu UD. Tabo Coffee Sipirok dan PDM (Pesantren Darul Mursyid) Kopi. Berikut merupakan hasil pemetaan dari rata-rata faktor-faktor kompetisi :

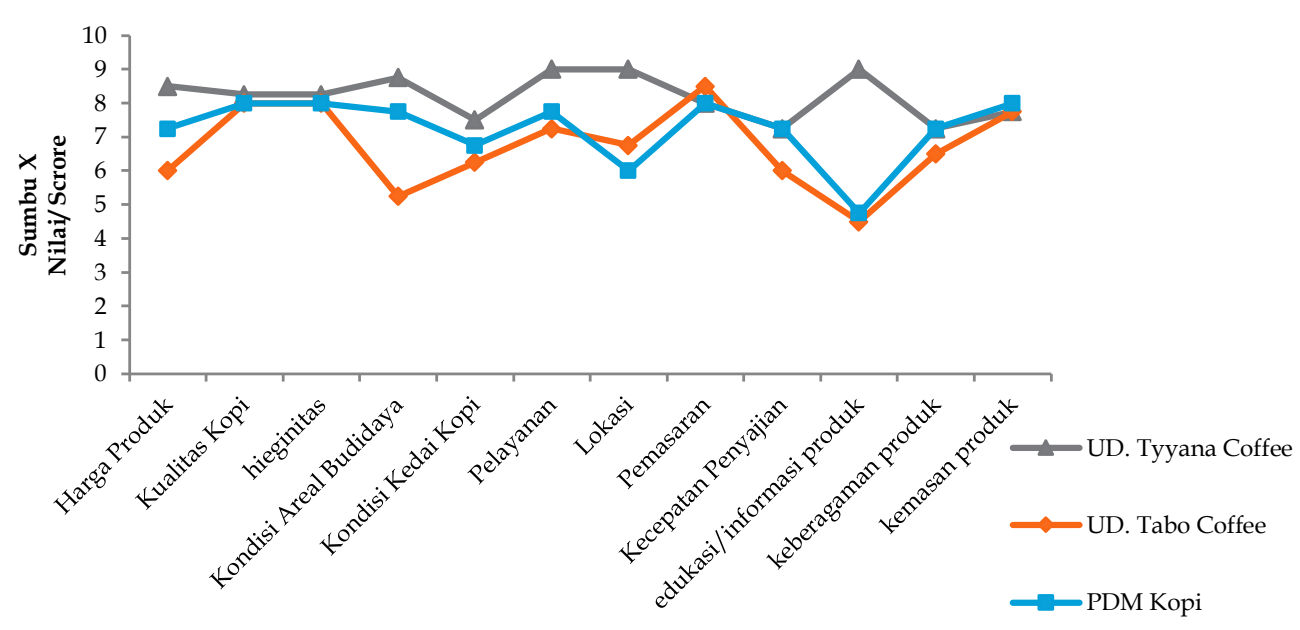

Gambar 1.

Kanvas Strategi Industri Pengolahan Kopi 
Berdasarkan gambar 1, UD. Tyyana Coffee memiliki kinerja yang tinggi terhadap faktor-faktor kompetisi yaitu harga produk, kondisi areal budidaya kopi, pelayanan, lokasi dan edukasi/informasi produk. Sedangkan kinerja yang rendah terhadap faktor kompetisi tidak ada. Untuk kinerja yang sama dengan pesaing terhadap faktor kompetisi yaitu kualitas kopi, hieginietas, pemasaran, keberagaman produk dan kemasan produk.

\section{Memenuhi Tiga Ciri Strategi Samudera Biru yang baik}

Menurut Kim (2006), dalam memformulasikan Blue Ocean Strategy, terdapat tiga karakteristik harus dipenuhi yaitu focus, divergensi atau gerak menjauh serta motto yang unik. Motto sangat berguna untuk positioning dan kenyamanan produk (Agantha, 2016). Berikut ciri samudera biru UD. Tyyana Coffee dapat dilihat pada tabel 1.

Tabel 1. Ciri Strategi Blue Ocean Yang Baik

\begin{tabular}{ll}
\hline \multirow{2}{*}{ Focus } & 1. Meningkatkan faktor-faktor yang berkinerja sangat \\
& rendah
\end{tabular}

Motto unik Dari kebun ke cangkir

\section{Prinsip 3: Menjangkau Permintaan}

Menjangkau permintaan melalui kerangka kerja empat langkah (four framework) yaitu suatu langkah kerja yang mengevaluasi faktor-faktor yang berpengaruh dalam penciptaan kurva nilai baru (Suhendar, 2009),dengan menemukan data atau informasi pada UD. Tyyana Coffee untuk dapat diciptakan, ditingkatkan, diturunkan dan dihilangkannya faktor-faktor bisnisnya. Skema ini memacu perusahaan agar tidak hanya bertanya mengenai kerangka empat jalan namun juga bertindak dengan menciptakan kurva bilai baru (Hamdani, 2018). Tabel 2 menyajikan skema kerangka kerja 4 jalan UD Tyyana Coffee. 
Tabel 2. Skema Kerangka Kerja 4 Jalan

\begin{tabular}{|c|c|}
\hline Menghapuskan & Meningkatkan \\
\hline 1. Fokus pada satu target pasar & $\begin{array}{l}\text { 1. Pelayanan } \\
\text { 2. Diversifikasi produk } \\
\text { 3. Kualitas SDM dan produk }\end{array}$ \\
\hline Mengurangi & Menciptakan \\
\hline 1. Ekspor barang & $\begin{array}{l}\text { 1. Tren lokasi bernuansa Cafe } \\
\text { 2. Homestay }\end{array}$ \\
\hline
\end{tabular}

Dari tabel 2 dapat dilihat bahwa dalam mengembangkan usaha berbasis bisnis, UD. Tyyana Coffee yaitu (1) menghapuskan fokus pada satu targer pasar dengan menjual produk kopi bentuk bahan baku maupun kopi siap seduh, (2) Mengurangi ekspor produk, karena produk bisa diolah sendiri dengan memperoleh nilai tambah dari kopi sehingga memperoleh harga jual yang tinggi, (3) Meningkatkan keberagaman produk yang dijual dan kualitas produk serta SDM (4) Menciptakan tren lokasi bernuansa Cafe dan homestay.

\section{Prinsip 4: Menjalankan Rangkaian Strategi Blue Ocean Strategi}

Keberlanjutan usaha akan tercipta dan kuat jika rangkaian strategi yang dijalankan sudah benar. Resiko bisnis akan berkurang saat ide-ide blue ocean strategi dipahami berlandaskan kriteria kunci sesuai nilai yang ada (Kim, 2006). UD.Tyyana Coffee harus melakukan rangkaian strategi yang benar dengan membangun utilitas pembeli, harga produk, biaya usaha dan pengadopsian inovasi (Lestari, 2017). Rangkaian strategi dapat dilihat dari manfaat internal maupun eksternal yang ditawarkan (Arifin, 2018). 


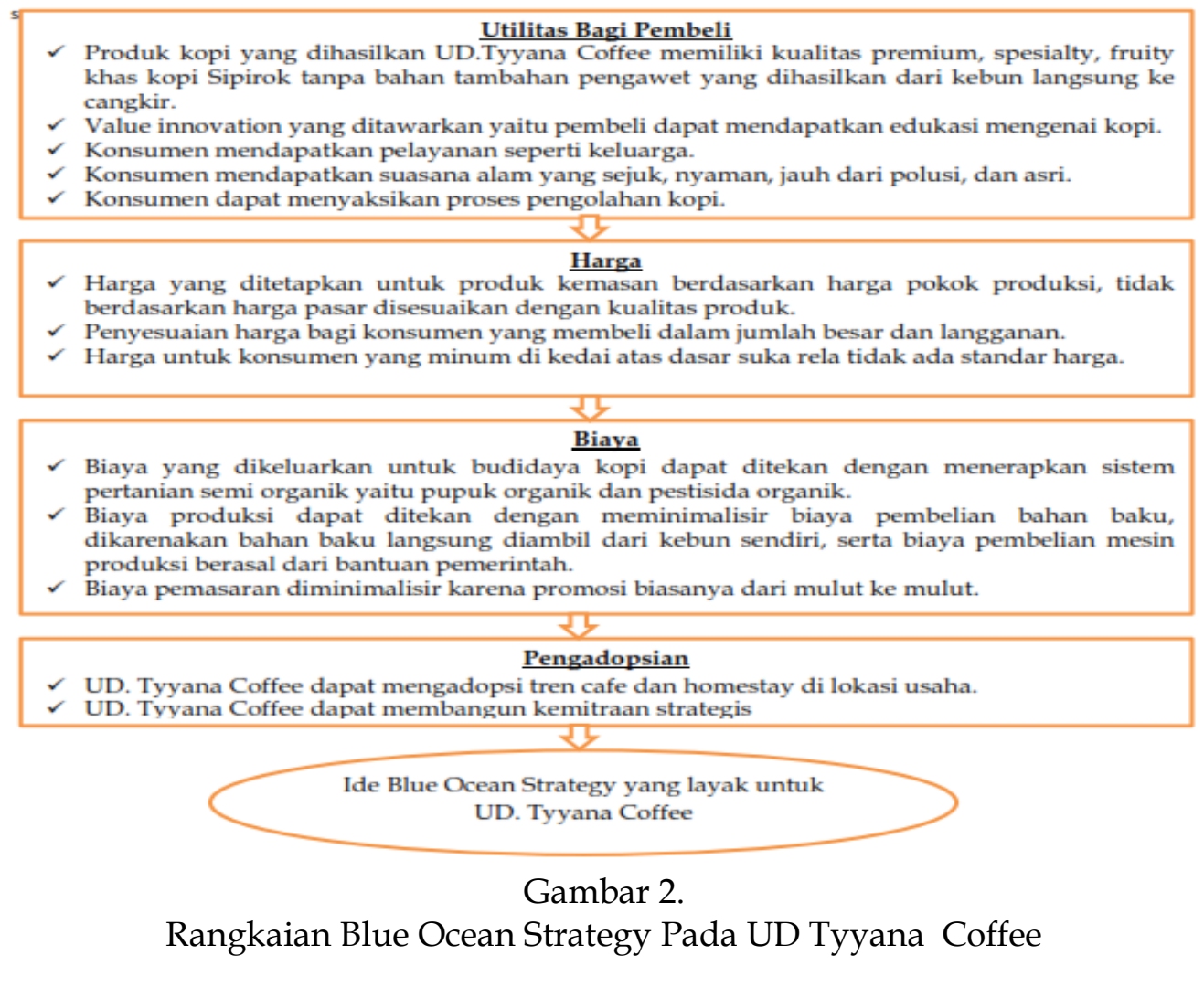

\section{SIMPULAN DAN SARAN}

\section{Simpulan}

Kesimpulan yang diperoleh dari penelitian yaitu Blue Ocean Strategy pada UD. Tyyana Coffe yaitu memecah strategi yang belum dimiliki oleh kompetitor, seperti (1) Meningkatkan kualitas produk dan SDM akan memberikan manfaat bagi konsumen dengan memberikan hasil yang maksimal. Menciptakan tren lokasi dengan nuansa kafe dan fasilitas seperti homestay akan meningkatkan daya tarik emosional konsumen, (2) harga yang ditawarkan UD. Tyyana Coffee sangat menarik dan tidak berubah, sehingga tidak mempengaruhi daya beli konsumen, (3) Biaya minimum, meningkatkan pelayanan diintensifkan saat menyajikan kopi dengan memberikan edukasi. (4) Mengadopsi Strategi Samudra Biru membutuhkan komitmen dan kerja sama dalam pekerjaannya. 


\section{Saran}

Saran yang diberikan yaitu:

1. Untuk UD. Tyyana Coffee sebaiknya melakukan pengembangan usaha berdasarkan strategi yang di tetapkan untuk mencapai keunggulan kompetitif yang berkelanjutan.

2. Bagi akademisi, sebaiknya melakukan penelitian lanjutan mengenai bagaimana strategi yang seharusnya dilakukan untuk mempertahankan keunggulan kompetitif berkelanjutan.

\section{DAFTAR PUSTAKA}

Agantha Mukhlis Yagi. 2016. Pengembangan Usaha Melalui Blue Ocean Strategy (BOS) Di Home Insdustry Liya. [skripsi]. Surakarta: Jurusan Teknik Industri Fakultas Teknik Universitas Muhammadiyah Surakarta. 16 hal. Andriani Meidina Megan. 2012. Strategi Pengembangan Usaha Restoran Gurih 7 Di Kota Bogor Dengan Pendekatan Blue Ocean Strategy. [skripsi]. Departemen Agribisnis. Fakultas Ekonomi dan Manajemen Intitut Pertanian Bogor. 126 hal.

Arifin Sarah Melinda dan Yusri Abdillah. 2018. Penerapan Blue Ocean Strategy (BOS) Dalam Usaha Memasuki Pasar Internasional (Studi Pada UMKM Pricilla Jilbab Bolak-Balik). Malang. Jurnal Administrasi Bisnis (JAB). 61(2): 38-47.

Badan Pusat Statistik Kabupaten Tapanuli Selatan. 2017. Kabupaten Tapanuli Selatan dalam Angka 2017.

Chandra Erbin. 2014. Peranan Kerjasama Bisnis Terhadap Peningkatan Volume Penjualan Pada Toko Media Print Pematangsiantar. Jurnal SULTANIST. 2(2): 5-11.

Hadi Prajogo U, Dkk. 2011. Outlok Pertanian 2010-2025. Badan Litbang Pertanian, Kementrian Pertanian. 74 hal.

Hamdani Muhammad. 2018. Analisis Penerapan Red Ocean Strategy dan Blue Ocean Strategy Menggunakan Skema Hapuskan-Kurangi-Tingkatkan-Ciptakan, Kanvas Strategi dan Indeks Samudra Biru pada Coffee Shop di Medan. [skripsi]. Medan: Departemen Administrasi Bisnis, Universitas Sumatera Utara. 80 hal.

Hermato. 2011. Implementation Blue Ocean Strategy (Strategi Samudra Biru) At Group Wings. Jurnal Ilmiah Faktor Exacta. 4(2): 149-159.

Kho, Michael, Christian Kosasih dan Ratih Indriyani. 2014. Perumusan Blue Ocean Strategy sebagai Strategy Bersaing Pada Perusahaan Keluarga Cv. Gama Abadi. Jurnal AGOVA. 2(1): 9 hal. 
Kim Chan W dan Renee Mauborgne. 2006. Blue Ocean Strategy Menciptakan Ruang Pasar tanpa Pesaing dan Menjadikan Persaingan Tidak Lagi Relevan. Jakarta: PT. Mizan Publika. 376 hal.

Lestari Fennika Ayu, dkk. 2017. Analisis Perbandingan Antara Red Ocean Strategy Versus Blue Ocean Strategy Terhadap Coffee Shop Di Yogyakarta. E-Jurnal Universitas Atma Jaya Yogyakarta. 1-14 Hal.

Mardalis Ahmad. 2005. Meraih Loyalitas Pelanggan. BENEFIT Jurnal Manajemen dan Bisnis. 9(2): 111-201.

Mussatto S.I dan Machado. 2011. Production, Composition and Application of Coffee and Its Industrial Residues. Journal Food Bioprocess Technology 4:5 661-672.

Mustamu Ronny H dan Garra Sugianto. 2013. Strategi Bersaing Pada Perusahaan Kopi. Jurnal AGORA. 1(3)

Pasolang Ambrose Deppa Runggu. 2012. Formulasi Strategi Pengembangan Wisata Kebun Raya Bogor Melalui Pendekatan Blue Ocean Strategy. [skripsi]. Bogor: Fakultas Ekonomi dan Manajemen, IPB.94 hal.

Putri Sri Rahayu Farida. 2018. Formulasi Strategy Bisnis Agrowisata Taman Buah Mekarsari Di Kabupaten Bogor Dengan Pendekatan Blue Ocean Strategy. [skripsi]. Bogor: Fakultas Ekonomi dan Manajemen, IPB. 69 hal.

Sari Intan Irma Permata. 2018. Pengaruh Tingkat Kematangan dan Konsentrasi Ciragi Terhadap Mutu Bubuk Kopi Arabika. [skripsi]. Padang: Fakultas Teknologi Pertanian Universitas Andalas. 72 hal.

Suhendar Usep. 2009. Kajian Strategi Pemasaran Ikan Asap (Smoked Fish) di UKM Petikan Cita Halus Citayam-Bogor. [tesis]. Bogor: Sekolah Pascasarjana Institut Pertanian Bogor. 166 hal.

Utomo Nugroho Bagus. 2010. Formulasi Strategi Waralaba Minuman Teh Siap Saji Your Tea dengan Pendekatan Blue Ocean Strategy. [skripsi]. Bogor: Fakultas Ekonomi dan Manajemen IPB. 122 hal.

Walker G. 2009. Modern Competitive Strategy. New York: McGraw-Hill Companies, Inc. 